\title{
DETECTION OF PATENT FORAMEN OVALE WITH CONTRAST ENHANCED TRANSCRANIAL DOPPLER AT DIVERS
}

\author{
Krzysztof Dziewiatowski ${ }^{1)}$, Piotr Siermontowski ${ }^{2,3)}$
}

1) Stroke Unit 7 Naval Hospital in Gdańsk, Poland

2) Department of Submarine Work Technology, Naval Academy in Gdynia, Poland

3) Maritime \& Hyperbaric Medicine Department, Military Institute of Medicine in Gdynia, Poland

\section{ABSTRACT}

Patent foramen ovale (PFO) is a condition present in $25 \%$ of the adult population. It is a remnant of fetal foramen ovale which allows blood to pass from the right to the left atrium, bypassing the fetal lungs. In majority adults it does not have any clinical significance, but in some people it may allow shunting of venous blood into the left atrium (right - left - shunt or RLS), circumventing the lung filter, especially during sneezing, cough, lifting heavy equipment. Is such case, PFO may be a route for venous emboli or gas bubbles from veins to the arterial system. It is known as a paradoxical embolism and may be cause of ischaemic stroke or neurologic decompression sickness $(\mathrm{DCl})$, inner-ear $\mathrm{DCl}$ and cutis marmorata. Transesophageal echocardiography is considered as a reference standard in detection of intracardial shunts. Its sensitivity and specificity ranges between $94 \%-100 \%$. However, TEE is an invasive examination with potentially serious side effects. An alternative examination in RLS detection is contrast enhanced Transcranial Doppler (the bubble study or C-TCD). In comparison to TEE, Transcranial Doppler is not invasive, relatively not expensive and save technique. With its high sensitivity and specificity in detection of PFO, $97 \%$ and $93 \%$ respectively, it may improve detection of RLS and allow to conduct screening examination for PFO in divers.

Keywords: persistent foramen ovale, scuba diving; right-to-left shunt, paradoxical embolism, decompression sickness, transcranial doppler ultrasonography.

\section{ARTICLE INFO}

PolHypRes 2019 Vol. 67 Issue 2 pp. 93 - 102

ISSN: 1734-7009 elSSN: 2084-0535

DOI: 10.2478/phr-2019-0008

Pages: 9, figures: 4 , tables: 0

page www of the periodical: www.phr.net.pl

Publisher

Polish Hyperbaric Medicine and Technology Society

\section{Review article}

Submission date: 03.09.2018 r.

Acceptance for print: 20.10.2018 r. 


\section{INTRODUCTION}

Patent foramen ovale (PFO) is an anatomical variant present in approximately $25 \%$ of the adult population which consists in maintaining a connection between the right and left atrium [1,2]. In a foetus, the foramen ovale is a very important structure which allows all of the circulating blood to flow through, bypassing the lungs, which do not function in foetal life. After the birth, the lungs are expanded, gas is exchanged in the alveoli, and pressure increases the in left atrium to the values exceeding right atrial pressure, which in normal conditions in most infants leads to closure of the foramen ovale during the first year of life [2].

In some healthy individuals, however, it does not close completely leaving a channel of varying diameter surrounded by connective tissue forming a kind of valve. While in the vast majority of cases PFO is clinically insignificant, in certain situations of right atrial pressure increase (coughing, sneezing, abdominal prelum, lifting heavy weights, pulmonary hypertension, tricuspid regurgitation, etc.) it may open and a short-term venous blood shunt from the right to the left atrium may occur the so-called venous-arterial shunt or right-left shunt (Fig. 1).

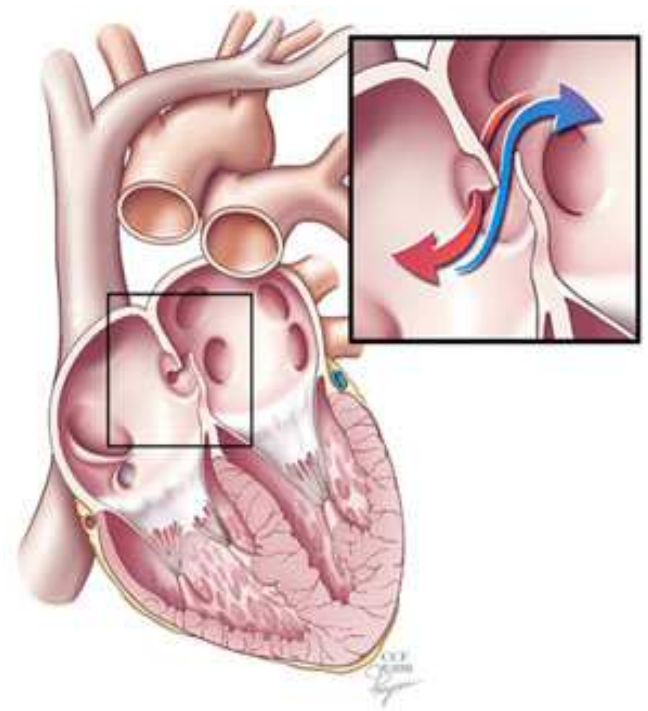

Fig. 1 A diagram showing patent foramen ovale. The blue and red arrow illustrates the mixing of venous and arterial blood. Source: https://my.clevelandclinic.org/-/scassets/images/org/health/articles/patent-foramen-ovale-02-heart-pfo-combo.ashx.

In the course of a venous-arterial shunt, paradoxical embolism may occur, where venous emboli or thrombi may pass from venous to arterial circulation causing ischaemic strokes $[3,4,5,6]$. While diving, the PFO may be the route for gas bubbles that appear during normal decompression or in the course of the decompression sickness, which may then penetrate arterial vessels. As a result of these emboli, a severe neurological form of decompression sickness may develop (with paresis and paralysis of limbs, sensory disorders, visual and speech disturbances, sphincter paralysis, disorientation or loss of consciousness after diving). $[7,8,9]$.

The presence of right-left shunt may also contribute to subclinical brain damage in divers as a result of embolism with microbubbles of gas during subsequent dives (even in the absence of decompression sickness in medical history) [10]. According to the current guidelines, a reference standard in the detection of the patent foramen ovale is transesophageal echocardiography (TEE) with an intravenous contrast administration, whose sensitivity and specificity in PFO detection reaches 94\%-100\%, compared to about $80-86 \%$ in the case of transthoracic echocardiography $[11,12,13]$, used e.g. in military medical certification.

With the introduction of the echocardiographic probe into the oesophagus, difficulties and artifacts related to the patient's obesity or presence of chest bone structures (sternum and ribs) can be eliminated. However, transesophageal examination is very often a great discomfort for the patient. It is also emphasized that some venous-arterial shunts (RLS - right - left shunts) may be overlooked in TEE due to the difficulties in performing the Valsalva maneuvre by patients $[11,14]$. Transesophageal echocardiography is an invasive examination, carrying a risk of potentially dangerous complications. Serious complications resulting from TEE are very rare $(0.2-0.6 \%)$ and include: oesophageal spasm, oesophageal perforation with mediastinitis, vocal cord injury, massive bleeding from the oesophageal tumour, cardiac arrhythmias including cardiac arrest, and death (less than 0.01\%) [15]. High cost and availability of the equipment also constitute a barrier limiting a wide use of TEE in diagnosing PFO.

An alternative to transesophageal echocardiography for detecting a venous-arterial shunt, is contrast enhanced ultrasound Doppler examination of intracranial arteries and arteries supplying the head ('blind doppler', Transcranial Doppler - TCD), which as a cheap, noninvasive and safe method characterized by very high sensitivity and specificity $(97 \%-100 \%$ and $93-98 \%$ respectively) $[11,14,16]$, and which may significantly improve the detection of cases of PFO with venous-arterial shunt and enable screening of divers and candidates for divers.

Devices for ultrasound Doppler examination of arteries supplying the head, as well as intracranial arteries 
('blind doppler', Transcranial Doppler - TCD) are widely used in Stroke Units to diagnose patients with ischaemic stroke. The first intracranial arterial flow tests were performed in 1982 and since then TCD has been proven as a useful method of detecting vascular diseases of the nervous system, including the detection of PFO $[11,14,16,17]$.

In the year 2000, a standard for the detection of a venous-arterial shunt by Doppler sonography was established[18], which has caused these studies to be highly sensitive and specific, to a degree comparable to transesophageal echocardiography $[11,14,16]$.

Contrast enhanced transcranial ultrasound (c-TCD) is based on monitoring the flow in cerebral vessels (middle cerebral artery) during intravenous contrast administration. Doppler ultrasound devices are used to evaluate the direction, velocity and spectral flow in the examined arteries ('blind doppler'). These devices do not provide information on the morphology of blood vessels, but they accurately assess the blood flow spectrum within them, and are able to detect the presence of microembolic elements, including microbubbles of gas flowing through the blood. Ready-to-use ultrasound contrasts containing micro-bubbles can be used in the diagnosis of venousarterial shunts. Due to their relatively high price, an equally effective contrast consisting of physiological saline with air bubbles suspended in it prepared ad hoc is widely used.

The patint is lying down during the examination. According to the standard [18], the patient requires a venipuncture of $18 \mathrm{G}$ into the basilic vein within the elbow bend before starting ultrasound examination. After the provision of venous access, classical Doppler examination of intracranial arteries and arteries supplying the head is performed. During this examination, the flow in carotid, vertebral, subclavian and cerebral arteries is evaluated. After the first phase of the examination, the patient has a band holding and stabilizing the $2 \mathrm{MHz}$ ultrasound probe for intracranial artery examination put on the head. During the examination, this probe will monitor blood flow in the middle cerebral artery (Fig. 2).

Once the correct spectral flow in the middle cerebral artery is reached, a contrast of physiological saline with air microbubbles suspended in it is administered in a bolus through a flexible tube to the basilic vein. The contrast is formed immediately prior to its administration as a result of vigorous mixing $9 \mathrm{~cm}^{3}$ of saline and $1 \mathrm{~cm}^{3}$ of air in two syringes connected by a three-way stopcock. Excess air is removed from the syringe before bolus administration (Fig. 3).

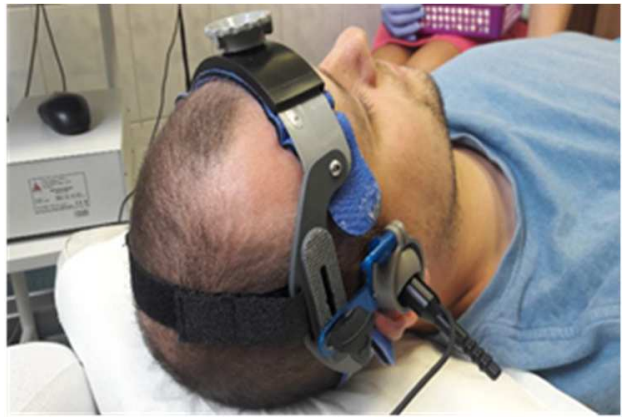

Fig. 2 A patient with a band stabilizing an ultrasound probe for intracranial artery examination. Source: own materials.

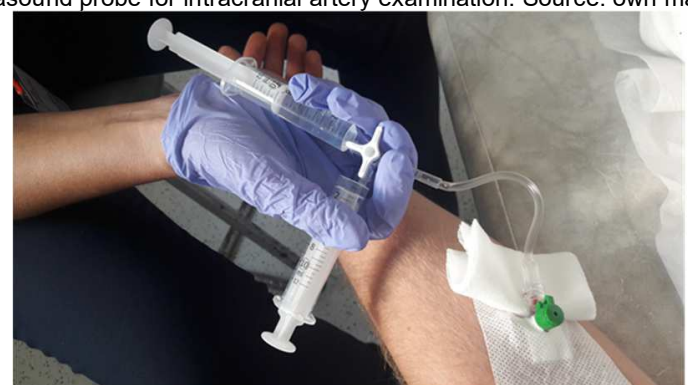

Fig. 3 Contrast preparation - visible syringes with air and saline connected by a three-way stopcock. Source: own materials.

Under physiological conditions, when there is no connection between pulmonary circulation and large circulation (venous blood does not mix with arterial blood), the microbubbles of air from the contrast are absorbed in the pulmonary alveoli and then released during exhalation and are therefore not detected in the middle cerebral artery. In the case of venous-arterial shunt (most commonly in the presence of PFO), some of the air microbubbles enter the arterial blood and will be recorded in the middle cerebral artery as signals corresponding to HITS (High Intensity Transient Signals) microembolism. They are characterized by short duration $(<300 \mathrm{~ms})$ and higher intensity ( $>3 \mathrm{~dB}$ above the background signal), which is clearly visible against the background of correct spectral flow in the monitored vessel. The detected signal is also accompanied by a characteristic short and intense sound reminiscent of a crack.

In order to increase sensitivity, a Valsalva maneuvre is performed on the patient during the examination - an increase in chest pressure enhances the probability of causing a blood shunt from the right to the left atrium through the foramen ovale. The Valsalva maneuvre is used only when HITS signals cannot be detected after intravenous contrast administration at rest, while breathing calmly. According to the procedure, the Valsalva maneuvre begins 5 seconds after the contrast is administered and should last 10 seconds. In a standard procedure, the assessment of signals of microembolism after contrast administration is made four times - once at rest and three times with accompanying Valsalva 
manoeuvre. If the first time a contrast is administered without the accompanying Valsalva maneuvre and numerous HITS signals, usually more than 30 , are detected, the examination is terminated to avoid air embolism, including in the retinal arteries. Throughout the procedure, the spectral flow in the middle cerebral artery should be monitored for approximately 60 seconds, and the appearance of HITS signals indicating microembolism caused by the right-left shunt should be tracked. The result of the test for the presence of RLS is considered negative if during three consecutive Valsalva manoeuvre trials no microembolism is found $[18,19]$.

After the test, the venous-arterial shunt rate is assessed on a four-grade scale (Fig. 4 and Tab. 1). Depending on the number of detected bubbles, a mild, moderate or severe shunt is defined [18].

A scale establishing right - left shunt (RLS) grade.

\begin{tabular}{ll}
\hline The number of HITS signals & Test result \\
\hline No microembolic signs & No RLS \\
\hline $1-10$ signals & Mild RLS \\
\hline Above 10 signals - quantifiable, not merging & Moderate RLS \\
\hline 'Rain' of signals - due to their merging, it is not possible to count individual signals & Severe RLS \\
\hline
\end{tabular}

Finding a venous-arterial shunt is not tantamount to the presence of the patent foramen ovale. Although PFO is by far the most common site of RLS, the shunt may also occur in the coexistence of other congenital heart defects, such as atrial septal defect or ventricular septal defect, and within the lungs through pulmonary arteriovenous fistulas. In order to unambiguously determine the location of the shunt, it may be necessary to extend the diagnosis with transesophageal echocardiography and chest X-ray.

Considering the prevalence of PFO, it should be emphasised that its clinical significance is low - it is responsible for some of the ischaemic strokes, especially in young people under 55 years of age, and may be a risk factor for a severe decompression sickness with neurological symptoms. In total, if all DCI episodes occur in about $0.005-0.08 \%$ of dives, the decompression sickness that can be associated with the presence of the patent foramen ovale amounts to $0.002-0.03 \%$ of exposures $[20,21]$. It should be noted that the risk of any decompression sickness varies significantly depending on the type of dives performed, from $1 / 3770$ dives in military divers, through $1 / 2900$ in recreational divers, to $1 / 290$ in heavy-duty commercial divers [22].

A lower percentage of DCI episodes in military divers is most likely due to their good health status, cardiovascular (including PFO) diagnostics, good training and rare decompression dives, which is particularly true for combat divers. It should also be emphasized that the risk of severe decompression disease increases with the increasing grade of the venous-arterial shunt. With mild RLS (up to 10 microbubbles), the risk of severe DCI is comparable to that of divers without PFO.

In the case of moderate or severe shunt, the risk increases, 4.4 times and 6.6 times respectively, compared to the risk in divers without PFO [23]. According to the published guidelines and recommendations [24,25], the search for PFO is not a prerequisite for every diver or candidate for a diver. However, diagnosis should be made in the case of recurrent episodes of decompression sickness, neurological or cutaneous DCI or episodes of decompression sickness not provoked by exceeding the diver's safety profile.

Detection is also recommended for commercial divers who have had episodes of severe, neurological or dermal DCI, especially with concomitant migraine with aura. A search for PFO should also be considered in cases of CNS ischaemic episodes of unclear cause and in cases of family history of PFO and atrial septal defect in first-degree relatives. It is also emphasized that one of the reasons for avoiding routine PFO screening in divers is high cost of transesophageal echocardiography and low risk of DCI episodes associated with venous-arterial shunts[24].

The regulations currently in force in Poland do not impose routine tests for PFO on professional divers (Regulation of the Minister of Health of 17 September 2007 on health conditions for underwater work [26] and its amendment from 2011 [27]). They only recommend that, in the event of deviations in clinical and function examinations, especially those indicating right-left shunt, a diver should be referred for specialized examinations. In the case of candidates for military divers, with regard to tests commissioned by the Military Maritime and Medical Committee, a standard transthoracic echocardiography is 
performed, where sensitivity and specificity in the detection of PFO reaches $80-86 \%$.

Due to the low risk of severe DCI, PFO detection does not seem necessary for all divers, especially recreational divers. However, it seems justified to develop screening standards for venous-arterial shunts (usually concomitant with the patent foramen ovale) in professional divers performing underwater work and military divers, which will increase the safety of diving. In order to avoid expensive and unpleasant transesophageal echocardiography, which is only available to a limited extent and carries a risk of potentially dangerous complications, contrast-enhanced Doppler intracranial artery examination can be used for screening. Sensitivity and specificity of c-TCD in PFO detection is comparable to transesophageal echocardiography, and other advantages include low examination cost, small size of ultrasound equipment, low invasiveness and no adverse effects associated with the test.

\section{REFERENCES}

1. Hagen PT, Scholz DG, Edwards WD. Incidence and size of patent foramen ovale during the first 10 decades of life: an autopsy study of 965 normal hearts. Mayo. Clin. Proc . 1984; 59:17-20. DOI: 10.1016/S0025-6196(12)60336-X;

2. Anderson RH, Webb S, Brown NA et al. Development of the heart: (2) Septation of the atriums and ventricles. Heart 2003; 89: 949-958, DOI 10.1136/heart.89.8.949;

3. Halperin JL, Fuster V, Patent foramen ovale and recurrent stroke: another paradoxical twist. Circulation 2002; 105 : $2580-2582$. doi.org/10.1161/01.CIR.0000020353.63751.2F

4. Webster MW, Chancellor AM, Smith HJ et al. Patent foramen ovale in young stroke patients. lancet 1988; 2: 11-12. DOI: 10.1016/s01406736(88)92944-3;

5. Lamy C, Giannesini C, Zuber $M$ et al. Clinical and imaging findings in cryptogenic stroke patients with and without patent foramen ovale: the PFOASA Study. Atrial Septal Aneurysm. Stroke 2002; 33: 706-711. DOI: 10.1161/hs0302.104543;

6. Homma S, Messé SR, Rundek T, Sun YP, Franke J, Davidson K, et al. , Patent Foramen Ovale, Nat Rev Dis Primers, 2016 Jan 21;2:15086. DOI: 10.1038/nrdp.2015.86;

7. Wilmshurst PT, Ellis BG, Jenkins BS. Paradoxical gas embolism in scuba diver with an atrial septal defect. Brit Med J1986;293:1277.DOI: 10.1136/bmj.293.6557.1277;

8. Guenzani S, Mereu D, Messersmith M, Olivari D. Arena M, Spano A, Inner-ear decompression sickness in nine trimix recreational divers. Diving Hyperb Med. 2016 Jun;46(2):111-6;

9. Vann RD, Butler FK, Mitchell SJ, Moon RE, Decompression Illness. Lancet. 2011. 2011 Jan 08;77(9760):153-64, DOI: 10.1016/S01406736(10)61085-9;

10. Schwerzmann M, Seiler C, Lipp E et al. Relation between direlectly detected patent foramen ovale and ischaemic brain lesions in sport divers. Ann Intern Med 2001; 134:21-4, DOI: 10.7326/0003-4819-134-1-200101020-00009;

11. González-Alujas T at al, Diagnosis and Quantification of Patent Foramen Ovale. Which Is the Reference Technique? Simultaneous Study With Transcranial Doppler, Transthoracic and Transesophageal Echocardiography., Rev Esp Cardiol. 2011;64(2):133-139, DOI: 10.1016/j.rec.2010.10.014;

12. Flaschkampf F, Decoodt P, Fraser A et al. Subgroup on Transesophegeal Echocardiography and Valvular Heart Disease; Working Group on Echocardiography of the European Society of Cardiology. Recommendations for performing transoesophageal echocardiography. Eur. J. Echocardiogr. 2001; 2: 8-21;

13. Flaschkampf F, Badano L, Daniel W et al. Recommendations for transoesophageal echocardiography - update 2010. Eur. J. Echocardiogr. 2010; 11: 557-576. DOI: 10.1093/ejechocard/jeq057;

14. Palazzo P, Ingrand P, Agius P, Belhadj Chaidi R, Neu JP, Transcranial Doppler to detect right-to-left shunt in cryptogenic acute ischaemic stroke. Brain and Behavior. 2019;9:e01091. DOI.org/10.1002/brb3.1091;

15. Szyszka A, Płońska-Gościniak E, Kasprzak JD, Gąsior Z, Tomasz Kukulski T, Gackowski A, et al., Rekomendacje 2011 Sekcji Echokardiografii Polskiego Towarzystwa Kardiologicznego dotyczące zastosowania echokardiografii przezprzełykowej w praktyce klinicznej, Kardiologia Polska 2011; 69, 7: 755-760., Polish [Recommendations of the Echocardiography Working Group of the Polish Cardiac Society for transesophageal echocardiography use in clinical practice 2011];

16. Mojadidi MK, Roberts SC, Winoker JS, Romero J, Goodman-Meza D, Gevorgyan R, et al. Accuracy of Transcranial Doppler for the Diagnosis of Intracardiac Right-to-Left Shunt: A Bivariate Meta-Analysis of Prospective Studies, JACC: Cardiovascular Imaging,, Volume 7, Issue 3, March 2014, Pages 236-250, DOI.org/10.1016/j.jcmg.2013.12.011;

17. Alexandrov A, Joseph M, Transcranial Doppler: An Overview of its Clinical Applications. The Internet Journal of Neurosurgery. 2000 Volume 1 Number 1, http://ispub.com/IJNS/1/1/12180;

18. Jauss M, Zanette E (2000). Detection of right- to- left shunt with ultrasound contrast agent and transcranial Doppler sonography. Cerebrovasc Dis 2000;10:490-496, DOI. org/10.1159/000016119;

19. Kozera G, Nyka WM, Próba TCD na PFO — znaczenie kliniczne i ograniczenia, Polski Przegląd Neurologiczny, 2008, tom 4, supl. A. Polish [PFO detection with use of transcranial Doppler. - clinical value and limitations];

20. Bove AA, Moon RE, Patent Foramen Ovale - Is It Important to Divers?

https://www.diversalertnetwork.org/medical/articles/Patent_Foramen_Ovale_Is_It_Important_to_Divers;

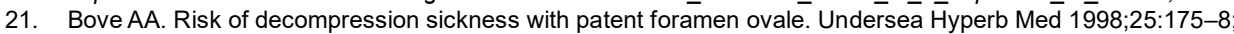

22. Garmonpre P. The medical risk of underwater diving and their control. Internat Sport Med Journal 2006:1-15, https://hdl.handle.net/10520/EJC48585;

23. Torti S.R., Billinger M., Schwerzmann M., Vogel R., Zbinden R., Windecker S., Seiler C., Risk of decompression illness among 230 divers in relation to the presence and size of patent foramen ovale, European Heart Journal, Volume 25, Issue 12, 1 June 2004, Pages 1014-1020, DOI: 10.1016/j.ehj.2004.04.028;

24. Sykes O, Clark JE. Patent foramen ovale and scuba diving: a practical guide for physicians on when to refer for screening. Extrem Physiol Med. 2013 Apr 1;2(1):10. DOI:10.1186/2046-7648-2-10;

25. Smart D, Mitchell S, Wilmshurst P, Turner M, Banham N. Joint position statement on persistent foramen ovale (PFO) and diving. South Pacific Underwater Medicine Society (SPUMS) and the United Kingdom Sports Diving Medical Committee (UKSDMC). Diving Hyperb Med. 2015 Jun;45(2):129-31; 
26. Regulation of the Minister of Health of 17 September 2007 on health conditions of performing underwater works, Journal of Laws 2007 No. 199 item 1440;

27. Regulation of the Minister of Health of 11 February 2011 amending the Regulation on health conditions for the performance of underwater works, Journal of Laws 2011 No. 40 item 211.

lek. med. Krzysztof Dziewiatowski kdziewiatowski@poczta.onet.pl

Oddział Udarowy

7 Szpital Marynarki Wojennej

ul. Polanki 117
80-305 Gdańsk

ORCID identifier No: 0000-0003-2557-3561 